\title{
BILANGAN KROMATIK LOKASI UNTUK GRAF AMALGAMASI BINTANG
}

\author{
FADHILAH SYAMSI \\ Program Studi Matematika, \\ Pascasarjana Fakultas Matematika dan Ilmu Pengetahuan Alam, Universitas Andalas, \\ Kampus UNAND Limau Manis Padang, Indonesia,
}

\begin{abstract}
Let $G=(V, E)$ be a connected graph and $c$ a coloring of $G$. For $i=1,2, \ldots, k$, we define the color classes $C_{i}$ as the set of vertices receiving color $i$. The color code $c_{\Pi}(v)$ of a vertex $v \in V(G)$ is the $k$-vector $\left(d\left(v, C_{1}\right), d\left(v, C_{2}\right), \ldots, d\left(v, C_{k}\right)\right)$, where $d\left(v, C_{i}\right)$ is the distance between $v$ and $C_{i}$. If all vertices of $G$ have distinct color codes, then $c$ is called a locating-coloring of $G$. The locating-coloring number of graph $G$, denoted by $\chi_{L}(G)$, is the smallest positive integer $k$ such that $G$ has a locating coloring with $k$ color. Let $K_{1, n_{i}}$ be star, where $n_{i}$ is the number of leaves of each star $K_{1, n_{i}}$. We define the vertex amalgamation of star, denoted by $S_{k,\left(n_{1}, \ldots, n_{k}\right)}$, as a graph obtained from stars $K_{1, n_{i}}$ by identifying one arbitrary leaf from each star. We define the edge amalgamation of star, denoted by $S_{k,\left(n_{1}, \ldots, n_{k}\right)}^{*}$, as a graph obtained by uniting an edge of each star. If $n_{i}=m$ for each $i$, then we denoted the vertex amalgamation of star as $S_{k, m}$ and the edge amalgamation of star as $S_{k, m}^{*}$. In this paper we discuss the locating coloring of $S_{k,\left(n_{1}, \ldots, n_{k}\right)}$ and $S_{k,\left(n_{1}, \ldots, n_{k}\right)}^{*}$.
\end{abstract}

Kata Kunci: Amalgamation of star, locating-chromatic number

\section{Pendahuluan}

Misalkan $c$ adalah suatu pewarnaan titik pada graf $G$ dengan menggunakan warnawarna $1,2, \ldots, k$ untuk suatu bilangan bulat positif $k$. Secara ekivalen, $c$ merupakan suatu partisi $\Pi$ dari $V(G)$ ke dalam kelas-kelas warna yang saling bebas $C_{1}, C_{2}, \ldots, C_{k}$, dimana titik-titik pada $C_{i}$ diberi warna $i, 1 \leq i \leq k$. Kode warna $c_{\Pi}(v)$ dari suatu titik $v \in V(G)$ didefinisikan sebagai $k$-vektor:

$$
c_{\Pi}(v)=\left(d\left(v, C_{1}\right), d\left(v, C_{2}\right), \ldots, d\left(v, C_{k}\right)\right)
$$

dimana $d\left(v, C_{i}\right)=\min \left\{d(v, x) \mid x \in C_{i}\right\}$ untuk $1 \leq i \leq k$. Jika setiap titik di $G$ memiliki kode warna yang berbeda terhadap partisi $\Pi$, maka $c$ disebut pewarnaan lokasi.

Kajian tentang pewarnaan lokasi adalah suatu kajian yang cukup baru dalam bidang teori graf. Konsep pewarnaan lokasi pertama kali dikaji oleh Chartrand dkk. [6] pada tahun 2002 dengan menentukan bilangan kromatik lokasi dari beberapa kelas graf sebagai berikut. Untuk graf lintasan $P_{n}$ dengan $n \geq 3$ diperoleh $\chi_{L}\left(P_{n}\right)=$ 3. Untuk graf siklus diperoleh dua hasil yaitu untuk $n$ ganjil berlaku $\chi_{L}\left(C_{n}\right)=$ 3 dan untuk $n$ genap berlaku $\chi_{L}\left(C_{n}\right)=4$. Selanjutnya, juga diperoleh $\chi_{L}(G)$ untuk graf multipartit lengkap dan dua graf bintang. Pada tahun 2003 Chartrand dkk. [7] membuktikan bahwa bilangan kromatik lokasi untuk graf $G$ dengan orde 
$n$ yang memuat graf multipartit lengkap berorde $n-1$ sebagai subgraf induksinya, berada pada selang $\left[\frac{(n+1)}{2}, n\right]$. Karena masih sedikit bilangan kromatik lokasi yang diketahui, maka topik pewarnaan lokasi menarik untuk dikaji lebih lanjut.

Misalkan terdapat $k$ buah graf bintang $K_{1, n_{i}}, n_{i} \geq 1$, untuk setiap $i=1,2, \ldots, k$ dengan $k, n_{i}$ adalah bilangan bulat. Graf amalgamasi titik bintang, $S_{k,\left(n_{1}, n_{2}, \ldots, n_{k}\right)}$, dengan $k \geq 2$, adalah graf yang diperoleh dengan mengidentifikasi sebuah daun dari setiap bintang. Titik hasil identifikasi disebut pusat amalgamasi, dinotasikan $x$. Titik yang berjarak satu dari pusat amalgamasi disebut titik tengah, dinotasikan $l_{i}, i=1,2, \ldots, k$ dan titik daun ke- $j$ dari titik tengah $l_{i}$ adalah $l_{i j}, j=1,2, \ldots, m-1$. Jika $n_{i}=m$ dengan $m \geq 1$ untuk semua $i$, graf amalgamasi titik dari bintang dinotasikan sebagai $S_{k, m}$. Graf amalgamasi sisi bintang, $S_{k,\left(n_{1}, n_{2}, \ldots, n_{k}\right)}^{*}$, untuk $k \geq 2$, adalah graf yang diperoleh dengan menyatukan sebuah sisi dari setiap graf $K_{1, n_{i}}$. Jika $n_{i}=m, m \geq 1$ untuk semua $i$, amalgamasi sisi dari $k$ graf bintang $K_{1, m}$ dinotasikan sebagai $S_{k, m}^{*}$.

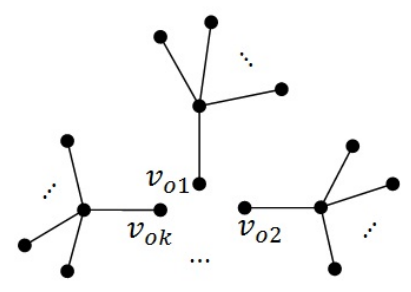

(a)

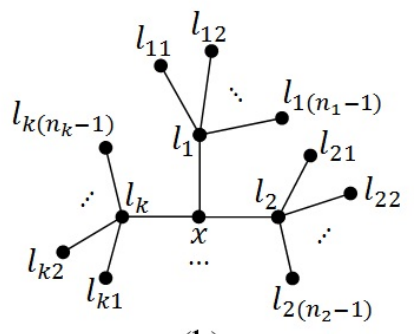

(b)

Gambar 1. (a) $k$ buah Graf Bintang $K_{1, n_{i}}$, (b) $S_{k,\left(n_{1}, n_{2}, \ldots, n_{k}\right)}$

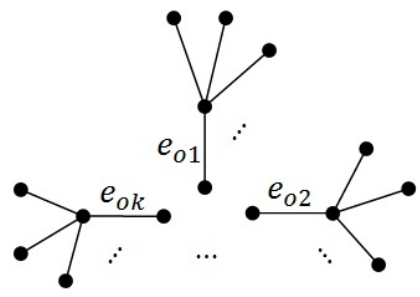

Gambar 2. (a) $k$ Buah Graf Bintang $K_{1, n_{i}}$, (b) $S_{k,\left(n_{1}, n_{2}, \ldots, n_{k}\right)}^{*}$

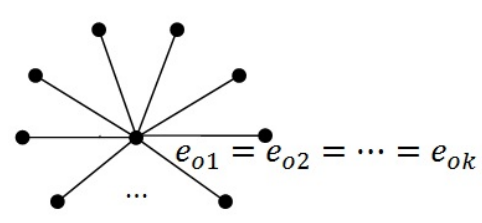

Suatu graf bintang $K_{1, n}$ mempunyai bilangan kromatik lokasi $n+1$ karena semua titik harus mempunyai kode warna yang berbeda. Jika $K_{1, m} \subseteq K_{1, n}$ maka $\chi_{L}\left(K_{1, m}\right) \leq \chi_{L}\left(K_{1, n}\right)$. Pada tulisan ini, akan dikaji sifat kemonotonan dari bilangan kromatik lokasi untuk graf amalgamasi bintang. Misalkan terdapat suatu amalgamasi dari $k$ graf bintang $K_{1, m}$, dinotasikan dengan $S_{k, m}$. Akan ditentukan syarat cukup untuk suatu subgraf terhubung $H \subseteq S_{k, m}$ sehingga dipenuhi 
$\chi_{L}(H) \leq \chi_{L}\left(S_{k, m}\right)$.

Teorema dan akibat dari Chartrand dkk. (2002) [6] berikut digunakan untuk menyelesaikan permasalahan pada penelitian ini.

Teorema 1.1. [5] Misal c adalah suatu pewarnaan lokasi pada graf terhubung G. Jika $u$ dan $v$ adalah dua titik pada graf $G$ sedemikian sehingga $d(u, w)=d(v, w)$ untuk setiap $w \in V(G) \backslash\{u, v\}$, maka $c(u) \neq c(v)$. Dalam hal khusus, jika u dan $v$ adalah titik-titik yang tidak bertetangga di $G$ sedemikian sehingga $N(u)=N(v)$, $\operatorname{maka} c(u) \neq c(v)$.

Bukti. Misalkan $c$ adalah suatu pewarnaan lokasi pada graf terhubung $G$ dan misalkan $\Pi=\left(C_{1}, C_{2}, \ldots, C_{k}\right)$ adalah partisi dari titik-titik $G$ ke dalam kelas warna $C_{i}$. Untuk suatu titik $u, v \in V(G)$, andaikan $c(u)=c(v)$ sedemikian sehingga titik $u$ dan $v$ berada dalam kelas warna yang sama, misal $C_{i}$ dari $\Pi$. Akibatnya, $d\left(u, C_{i}\right)=d\left(v, C_{i}\right)=0$. Karena $d(u, w)=d(v, w)$ untuk setiap $w \in V(G) \backslash\{u, v\}$ maka $d\left(u, C_{j}\right)=d\left(v, C_{j}\right)$ untuk setiap $j \neq i, 1 \leq j \leq k$. Akibatnya, $c_{\Pi}(u)=c_{\Pi}(v)$ sehingga $c$ bukan pewarnaan lokasi. Dengan demikian, $c(u) \neq c(v)$.

Akibat 1.2. [5] Jika $G$ adalah suatu graf terhubung yang memuat suatu titik yang bertetangga dengan $k$ daun di $G$, maka $\chi_{L}(G) \geq k+1$.

Bukti. Misalkan $v$ adalah suatu titik yang bertetangga dengan $k$ daun $x_{1}, x_{2}, \ldots, x_{k}$ di $G$. Dari Teorema 1.1 setiap pewarnaan lokasi dari $G$ mempunyai warna berbeda untuk setiap $x_{i}, i=1,2, \ldots, k$. Karena $v$ bertetangga dengan semua $x_{i}$, maka $v$ harus mempunyai warna yang berbeda dengan semua daun $x_{i}$. Akibatnya, $\chi_{L}(G) \geq k+\mathrm{\square}$

\section{Bilangan Kromatik Lokasi untuk Graf Amalgamasi Titik Bintang}

Pada [1], Asmiati, Assiyatun, dan Baskoro memberikan nilai bilangan kromatik lokasi untuk graf amalgamasi titik bintang. Pada bagian ini, penulis akan mengkaji kembali bilangan kromatik lokasi untuk graf amalgamasi titik bintang.

Lema 2.1. [1] Misalkan c adalah pewarnaan dari $S_{k, m}$ menggunakan paling sedikit $m$ warna dengan $k, m \geq 2$. Pewarnaan $c$ adalah pewarnaan lokasi jika dan hanya jika $c\left(l_{i}\right)=c\left(l_{n}\right), i \neq n$ mengakibatkan $\left\{c\left(l_{i j}\right) \mid j=1,2, \ldots, m-1\right\}$ dan $\left\{c\left(l_{n j}\right) \mid j=\right.$ $1,2, \ldots, m-1\}$ adalah dua himpunan yang berbeda.

Bukti. Misalkan $P=\left\{c\left(l_{i j}\right) \mid j=1,2, \ldots, m-1\right\}$ dan $Q=\left\{c\left(l_{n j}\right) \mid j=1,2, \ldots, m-1\right\}$. Misalkan $c$ adalah suatu pewarnaan lokasi dari $S_{k, m}, k \geq 2$ dan $m \geq 2$ menggunakan paling sedikit $m$ warna dan $c\left(l_{i}\right)=c\left(l_{n}\right)$ untuk beberapa $i \neq n$. Misalkan $\Pi$ adalah partisi dari $V(G)$ ke dalam kelas warna dengan $|\Pi| \geq m$. Andaikan $P=Q$. Karena $d\left(l_{i}, u\right)=d\left(l_{n}, u\right)$ untuk setiap $u \in V \backslash\left\{\left\{l_{i j} \mid j=1,2, \ldots, m-1\right\} \cup\left\{l_{n j} \mid j=\right.\right.$ $1,2, \ldots, m-1\}\}$ maka kode warna dari $l_{i}$ dan $l_{n}$ akan sama. Hal ini kontradiksi dengan pengandaian bahwa $c$ adalah pewarnaan lokasi. Dengan demikian $P \neq Q$. Selanjutnya, perhatikan bahwa $c\left(l_{i}\right)=c\left(l_{n}\right), i \neq n$. Karena $P \neq Q$, terdapat warna 
$y$ dan warna $z$ sedemikian sehingga $(y \in P, y \notin Q)$ dan $(z \notin P, z \in Q)$. Akan ditunjukkan bahwa kode warna untuk setiap $v \in V\left(S_{k, m}\right)$ adalah tunggal, yaitu sebagai berikut.

(1) Akan diperiksa kode warna dari titik-titik tengah yang mempunyai warna yang sama. Berdasarkan ilustrasi di atas, diperoleh bahwa:

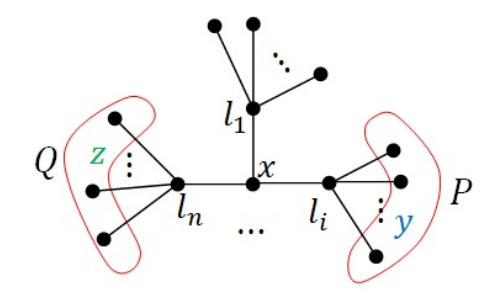

Gambar 3. Graf $S_{k, m}$ dengan $P \neq Q$

- Jika $c(x)=y$ maka

$$
\begin{gathered}
c_{\Pi}\left(l_{i}\right)=(\ldots, \underbrace{1}_{\text {ordinat ke- } y}, \ldots, \underbrace{\underbrace{2 \text { atau } 3}_{\text {ordinat ke- } z}}_{1}, \ldots) \\
c_{\Pi}\left(l_{n}\right)=(\ldots, \overbrace{1}^{\text {ord }}, \ldots)
\end{gathered}
$$

- Jika $c(x)=z$ maka

$$
\begin{gathered}
c_{\Pi}\left(l_{i}\right)=(\ldots, \underbrace{1}_{\text {ordinat ke- } y}, \ldots, \underbrace{1}_{\overbrace{2 \text { atau } 3}^{1}}, \ldots, \overbrace{\overbrace{1}^{\text {ordinat ke- } z}}^{1}, \ldots) \\
c_{\Pi}\left(l_{n}\right)=(\ldots, \ldots)
\end{gathered}
$$

- Jika $c(x)$ selain $y$ dan $z$ maka

$$
\begin{gathered}
c_{\Pi}\left(l_{i}\right)=(\ldots, \underbrace{1}_{\text {ordinat ke- } y}, \ldots, \overbrace{2 \text { atau } 3}^{2 \text { atau } 3}, \ldots) \\
c_{\Pi}\left(l_{n}\right)=(\ldots, \overbrace{1}^{\text {ordinat ke- } z}, \ldots)
\end{gathered}
$$

Dengan demikian, kode warna berbeda di ordinat ke- $y$ atau ordinat ke- $z$. Akibatnya, $c_{\Pi}\left(l_{i}\right) \neq c_{\Pi}\left(l_{n}\right)$.

(2) Akan diperiksa kode warna dari daun-daun yang mempunyai warna yang sama. Jika $c\left(l_{k l}\right)=c\left(l_{r s}\right)$, untuk beberapa $l_{k} \neq l_{r}$, akan ditunjukkan bahwa $c_{\Pi}\left(l_{k l}\right) \neq$ $c_{\Pi}\left(l_{r s}\right)$. Perhatikan dua kasus:

- Kasus 1. Jika $c\left(l_{k}\right)=c\left(l_{r}\right)$ maka berdasarkan premis Lema 2.1 diperoleh $P \neq Q$. Jadi, $c_{\Pi}\left(l_{k l}\right) \neq c_{\Pi}\left(l_{r s}\right)$.

- Kasus 2. Misalkan $c\left(l_{k}\right)=t_{1}$ dan $c\left(l_{r}\right)=t_{2}$, dengan $t_{1} \neq t_{2}$. Maka $c_{\Pi}\left(l_{k l}\right) \neq$ $c_{\Pi}\left(l_{r s}\right)$ karena kode warna berbeda paling sedikit di ordinat ke- $t_{1}$ dan ordinat ke- $t_{2}$, yaitu

$$
c_{\Pi}\left(l_{k l}\right)=(\ldots, \underbrace{1}, \ldots, \underbrace{2,3 \text { atau } 4}, \ldots)
$$




$$
c_{\Pi}\left(l_{r s}\right)=(\ldots, \overbrace{2,3, \text { atau } 4}^{\text {ordinat ke- } t_{1}}, \ldots, \overbrace{\overbrace{1}^{\text {ordinat ke- } t_{2}}}^{\text {ord }}, \ldots)
$$

(3) Akan diperiksa kode warna dari titik tengah dan daun yang mempunyai warna yang sama.

Jika $c\left(l_{i}\right)=c\left(l_{n j}\right), l_{i} \neq l_{n}$ maka $c_{\Pi}\left(l_{i}\right)$ memuat paling sedikit dua komponen dengan nilai 1 , sedangkan $c_{\Pi}\left(l_{n j}\right)$ memuat tepat satu komponen dengan nilai 1, yaitu

$$
\begin{gathered}
c_{\Pi}\left(l_{i}\right)=(\ldots, \underbrace{1}_{\text {ordinat ke-c } c(x)}, \ldots, \underbrace{1}_{\text {ordinat ke- } c\left(l_{n}\right)}, \ldots) \\
c_{\Pi}\left(l_{n j}\right)=(\ldots, \underbrace{1} \underbrace{1} \operatorname{ke}-c\left(l_{i j}\right)
\end{gathered}
$$

Dengan demikian $c_{\Pi}\left(l_{i}\right) \neq c_{\Pi}\left(l_{n j}\right)$.

(4) Akan diperiksa kode warna dari titik pusat amalgamasi dan daun yang mempunyai warna yang sama.

Misal $c(x)=c\left(l_{i j}\right)$. Karena $k \geq 2$, maka kode warna dari $c_{\Pi}(x)$ memuat paling sedikit dua komponen dengan nilai 1 , sedangkan $c_{\Pi}\left(l_{i j}\right)$ memuat tepat satu komponen dengan nilai 1 , yaitu

$$
\begin{gathered}
c_{\Pi}(x)=(\ldots, \underbrace{1}_{\text {ordinat ke- } c\left(l_{i}\right)}, \cdots), \underbrace{\text { ordinat ke- } c\left(l_{i}\right)}, \ldots) \\
c_{\Pi}\left(l_{i j}\right)=(\ldots, \underbrace{1}_{\text {orde- } c\left(l_{n}\right)}, \ldots)
\end{gathered}
$$

Dengan demikian $c_{\Pi}(x) \neq c_{\Pi}\left(l_{i j}\right)$.

Dari semua kasus di atas, dapat dilihat bahwa kode warna untuk setiap titik di $S_{k, m}$ adalah tunggal. Dengan demikian $c$ adalah pewarnaan lokasi.

Lema 2.2. [1] Misal c adalah pewarnaan lokasi dari $S_{k, m}$ menggunakan $m+a$ warna dan $H(a)=(m+a-1)\left(\begin{array}{c}m+a-1 \\ m-1\end{array}\right), a \geq 0$, maka $k \leq H(a)$.

Bukti. Misal $c$ adalah pewarnaan lokasi dari $S_{k, m}$ menggunakan $m+a$ warna. Untuk suatu titik tetap $i$, misal $c\left(l_{i}\right)$ warna dari titik tengah $l_{i}$, maka banyak kombinasi warna yang digunakan oleh $\left\{l_{i j} \mid j=1,2, \ldots, m-1\right\}$ adalah $\left(\begin{array}{c}m+a-1 \\ m-1\end{array}\right)$. Karena satu warna digunakan untuk titik pusat amalgamasi $x$, maka terdapat $(m+a-1)$ warna untuk $l_{i}$, untuk setiap $i=1,2, \ldots, k$. Dari Lema 2.1, diperoleh nilai maksimum dari $k$ adalah $(m+a-1)\left(\begin{array}{c}m+a-1 \\ m-1\end{array}\right)=H(a)$. Jadi, $k \leq H(a)$.

Teorema berikut memberikan nilai bilangan kromatik lokasi untuk graf amalgamasi titik bintang.

Teorema 2.3. Diberikan bilangan bulat $a \geq 0, k \geq 2, m \geq 3$. Jika $H(a)=(m+$ 
$a-1)\left(\begin{array}{c}m+a-1 \\ m-1\end{array}\right)$, maka

$$
\chi_{L}\left(S_{k, m}\right)=\left\{\begin{array}{cl}
m & ; \text { untuk } 2 \leq k \leq H(0), m \geq 3 \\
m+a & ; \text { untuk } H(a-1)<k \leq H(a), a \geq 1
\end{array}\right.
$$

Bukti. Pertama-tama akan dicari batas bawah dan batas atas dari $\chi_{L}\left(S_{k, m}\right)$ untuk $2 \leq k \leq H(0)=m-1$.

(1) Batas bawah dari $\chi_{L}\left(S_{k, m}\right)$.

Dari Akibat 1.2, setiap titik $l_{i}$ bertetangga dengan $(m-1)$ daun, untuk $i=$ $1,2, \ldots, k$. Dengan demikian $\chi_{L}\left(S_{k, m}\right) \geq m$.

(2) Batas atas dari $\chi_{L}\left(S_{k, m}\right)$.

Misalkan $c$ adalah pewarnaan dari $V\left(S_{k, m}\right)$ menggunakan $m$ warna. Tanpa mengurangi keumuman, misal $c(x)=1$ dan $c\left(l_{i}\right)=i+1$ untuk $i=1,2, \ldots, k$. Karena daun-daun harus mempunyai kode warna yang berbeda, maka daundaun $\left\{l_{i j} \mid j=1,2, \ldots, m-1\right\}$ diberi warna oleh $\{1,2, \ldots, m\} \backslash\{i+1\}$ untuk sebarang $i$. Maka, berdasarkan Lema 2.1, $c$ adalah pewarnaan lokasi. Dengan demikian $\chi_{L}\left(S_{k, m}\right) \leq m$.

Selanjutnya, akan dicari batas bawah dan batas atas untuk $H(a-1)<k \leq$ $H(a), a \geq 1$, yaitu sebagai berikut.

(1) Batas bawah dari $\chi_{L}\left(S_{k, m}\right)$.

Karena $k>H(a-1)$, maka berdasarkan Lema $2.2 \chi_{L}\left(S_{k, m}\right) \geq m+a$. Pada sisi lain, jika $k>H(a)$ maka berdasarkan Lema $2.2, \chi_{L}\left(S_{k, m}\right) \geq m+a+1$. Dengan demikian, $\chi_{L}\left(S_{k, m}\right) \geq m+a$ jika $H(a-1)<k<H(a)$.

(2) Batas atas dari $\chi_{L}\left(S_{k, m}\right)$.

Misalkan $c(x)=1$ dan warna dari titik tengah $l_{i}$ adalah $2,3, \ldots, m+a$. Karena $H(a-1)<k \leq H(a), a \geq 1$ maka banyak titik tengah yang mempunyai warna $t$ yang sama tidak lebih dari $\left(\begin{array}{c}m+a-1 \\ m-1\end{array}\right)$, untuk sebarang $t$. Akibatnya, jika $c\left(l_{i}\right)=c\left(l_{n}\right), i \neq n$ dapat diatur $\left\{c\left(l_{i j}\right) \mid j=1,2, \ldots, m-1\right\} \neq\left\{c\left(l_{n j}\right) \mid j=\right.$ $1,2, \ldots, m-1\}$. Berdasarkan Lema 2.1, $c$ adalah pewarnaan lokasi pada $S_{k, m}$. Jadi, $\chi_{L}\left(S_{k, m}\right) \leq m+a$ untuk $H(a-1)<k \leq H(a)$.

Teorema berikut menjelaskan tentang sifat kemonotonan dari bilangan kromatik lokasi graf amalgamasi titik bintang.

Teorema 2.4. [1] Jika $2 \leq k \leq m-1$, maka $\chi_{L}(G) \leq \chi_{L}\left(S_{k, m}\right)$ untuk setiap $G \subseteq S_{k, m}$ dan $G \neq K_{1, m}$.

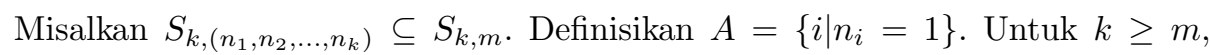
batasi subgraf dari $S_{k, m}$ yang memenuhi sifat kemonotonan.

Teorema 2.5. [1] Jika $k \geq m$ dan $|A| \leq \chi_{L}\left(S_{k, m}\right)-1$ maka

$$
\chi_{L}\left(S_{k,\left(n_{1}, n_{2}, \ldots, n_{k}\right)}\right) \leq \chi_{L}\left(S_{k, m}\right) .
$$




\section{Bilangan Kromatik Lokasi untuk Graf Amalgamasi Sisi Bintang}

Selain membahas kembali bilangan kromatik lokasi untuk graf amalgamasi titik bintang, yang merujuk makalah [2], penulis memberikan kontribusi pada bilangan kromatik lokasi untuk graf amalgamasi sisi bintang yang dibahas pada bagian ini.

Teorema 3.1. Jika terdapat bilangan bulat $k, m \geq 2$, maka

$$
\chi_{L}\left(S_{k, m}^{*}\right)=k(m-1)+2 \text {. }
$$

Bukti. Diberikan $k$ buah graf $K_{1, m}$. Graf amalgamasi sisi bintang dari graf $K_{1, m}$ adalah $S_{k, m}^{*}$ dengan titik pusat $v$. Banyak daun dari graf $S_{k, m}^{*}$ adalah

$$
\begin{aligned}
\left|V\left(S_{k, m}^{*}\right) \backslash v\right| & =\sum_{i=1}^{k}(m-1)+1 \\
& =k(m-1)+1 .
\end{aligned}
$$

Karena $v$ bertetangga dengan $k(m-1)+1$ daun, maka berdasarkan Teorema 1.1 titik $v$ mempunyai warna yang berbeda dengan setiap daun $S_{k, m}^{*}$. Akibatnya, $\chi_{L}\left(S_{k, m}^{*}\right)=$ $k(m-1)+2$.

Teorema 3.2. Jika terdapat bilangan bulat $k, n_{i} \geq 2$, maka

$$
\chi_{L}\left(S_{k,\left(n_{1}, n_{2}, \ldots, n_{k}\right)}^{*}\right)=\sum_{i=1}^{k}\left(n_{i}\right)-(k-2) .
$$

Bukti. Diberikan $k$ buah graf $K_{1, n_{i}}$ dengan $n_{i} \geq 2$. Graf amalgamasi sisi dari graf $K_{1, n_{i}}$ adalah $S_{k,\left(n_{1}, n_{2}, \ldots, n_{k}\right)}^{*}$ dengan titik pusat $v$. Banyak daun dari graf $S_{k,\left(n_{1}, n_{2}, \ldots, n_{k}\right)}^{*}$ adalah

$$
\begin{aligned}
\left|V\left(S_{k,\left(n_{1}, n_{2}, \ldots, n_{k}\right)}^{*}\right) \backslash v\right| & =\sum_{i=1}^{k}\left(n_{i}-1\right)+1 \\
& =\left[\left(n_{1}-1\right)+\left(n_{2}-1\right)+\ldots+\left(n_{k}-1\right)\right]+1 \\
& =\left(n_{1}+n_{2}+\ldots+n_{k}\right)-k+1 \\
& =\sum_{i=1}^{k}\left(n_{i}\right)-(k-1) .
\end{aligned}
$$

Karena $v$ bertetangga dengan $\sum_{i=1}^{k}\left(n_{i}\right)-(k-1)$ daun, maka berdasarkan Teorema 1.1 titik $v$ mempunyai warna yang berbeda dengan setiap daun $S_{k,\left(n_{1}, n_{2}, \ldots, n_{k}\right)}^{*}$. Akibatnya, $\chi_{L}\left(S_{k,\left(n_{1}, n_{2}, \ldots, n_{k}\right)}^{*}\right)=\sum_{i=1}^{k}\left(n_{i}\right)-(k-2)$.

\section{Daftar Pustaka}

[1] Asmiati, H. Assiyatun, dan E.T. Baskoro. 2011. Locating-chromatic number of amalgamation of stars. ITB J. Sci. no.1. 43:1-8.

[2] Bondy, J. A dan U. S. R Murty. 2008. Graph Theory. Springer. United States.

[3] Budayasa, Ketut. 2007. Teori Graf dan Aplikasinya. Universitas Negeri Surabaya. 
[4] Chartrand, G. dan P. Zhang. 2005. Introduction to Graph Theory. McGraw-Hill. Boston.

[5] Chartrand, G., dkk. 2002. The locating-chromatic number of a graph. Bull. Inst. Combin. Appl. 36:89-101.

[6] Chartrand, G., dkk. 2003. Graph of order $n$ with locating-chromatic number n-1. Discrete Math. 269:65-79.

[7] Hartsfield, N. dan G. Ringel. 1994. Pearls in Graph Theory: A Comprehensive Introduction, Revised and Augmented. Academic Press, San Diego. 